\section{Characterization and Pathogenicity of Stem Blight Complex Isolates Associated with Stem Blight Disease on Vaccinium Species}

\author{
Ebrahiem M. Babiker', Stephen J. Stringer, Hamidou F. Sakhanokho, \\ and Barbara J. Smith \\ U.S. Department of Agriculture, Agricultural Research Service, Thad \\ Cochran Southern Horticulture Laboratory, 810 Hwy 26W, Poplarville, \\ MS, 39470

\section{James J. Polashock Improvement of Fruits and Vegetables Laboratory, Chatsworth, NJ 08019} \\ U.S. Department of Agriculture, Agricultural Research Service, Genetic
}

Additional index words. Vaccinium, Botryosphaeria, Neofusicoccum, blueberry, stem blight

Abstract. Species of Botryosphaeria and Neofusicoccum are major pathogens of blueberry worldwide. Accurate identification of these species is essential for developing effective management practices. A multigene sequencing strategy was used to distinguish between six isolates of stem blight pathogens collected from two different regions of the United States. The temperature growth study revealed that the optimal temperature for growth of five of the tested isolates ranged from 25 to $30{ }^{\circ} \mathrm{C}$, although no significant difference was detected for the growth of Neofusicoccum spp. isolate SD16-86 at 20, 25, 30, and $35{ }^{\circ} \mathrm{C}$. In vitro fungicide assays showed four fungicides, cyprodinil + fludioxonil, propiconazole, pyraclostrobin + boscalid, and azoxystrobin, were effective against the tested isolates with isolate SD16-86 being less sensitive compared with the other isolates. In a detached stem assay, none of 39 blueberry accessions displayed immunity or a high level of resistance to the two tested isolates, and no significant difference in lesion length was detected among the seven tested Vaccinium species inoculated with the two isolates.

Blueberries rank as the second most important berry crop in North America with a total area of 96,869 ha (Strik, 2006). As blueberry acreage increases, pathogen diversity and diseases become a more important issue. Stem blight, caused by the species complex of Botryosphaeria Moug.:Fr and Neofusicoccum, Crous, Slippers and A. J. L. Phillips, is considered one of the most common diseases limiting the establishment of blueberry plantings in the southeastern United States (Ballington et al., 1993; Wright and Harmon, 2010). In addition to blueberry, these causal fungi infect other woody plants, thus increasing the likelihood that fieldgrown blueberry plants will be exposed to inoculum of these pathogens. Species of

Received for publication 8 Mar. 2019. Accepted for publication 17 Apr. 2019.

The use of trade, firm, or corporation names in this publication is for the information and convenience of the reader. Such use does not constitute an official endorsement or approval by the United States Department of Agriculture or the Agricultural Research Service of any product or service to the exclusion of others that may be suitable. We are very grateful to Jennifer Carrol and Melinda A. Miller-Butler for their technical assistance.

${ }^{1}$ Corresponding author. E-mail: Ebrahiem.Babiker@ ars.usda.gov.

This is an open access article distributed under the CC BY-NC-ND license (https://creativecommons. org/licenses/by-nc-nd/4.0/).
Disease symptoms include reddening and drying of leaves, wilting of infected shoots, and plant death as the pathogen spreads (Polashock et al., 2017; Wright and Harmon, 2010). Incidence of stem blight has been increasing in the United States, and the disease has been reported in many other countries, including Mexico (Boyzo-Marin et al., 2016), New Zealand (Tennakoon et al., 2018), and China (Yu et al., 2012). Various management strategies have been recommended to reduce the severity of the disease, including irrigation management (Creswell and Milholland, 1988), use of resistant cultivars and clean planting stock, and selective pruning of infected parts (Weaver, 1978). Information about fungicide sensitivity could be used to reduce the severity of the disease when applied after pruning or injury to plants. Efficacy of fungicides to control the growth of $B$. dothidea was determined in a previous study using a detached stem assay. Stems treated with cyprodinil, fludioxonil, and pyraclostrobin developed lesions shorter than those of nontreated control (Smith and Miller-Butler, 2017b).

For U.S. producers to maintain competitiveness, new and highly productive cultivars possessing enhanced tolerance to biotic and abiotic stresses are needed. However, identifying the causal pathogen(s) is critical before developing resistant cultivars as well as implementing effective management and quarantine strategies. Breeding for disease resistance relies on accurate identification of the causal pathogens before incorporating genes for resistance. Resistance of certain half-high and lowbush blueberry cultivars to Botryosphaeria has been reported (Polashock and Kramer, 2006). Southern highbush blueberry (species complex between $V$. corymbosum L. $2 n=4 x=48$ and $V$. darrowii Camp $2 n=2 x=24$ ) breeders

(fom infected plants to healthy plants by healthy plants by wi rain, and field equipment (Milholland, 1972).

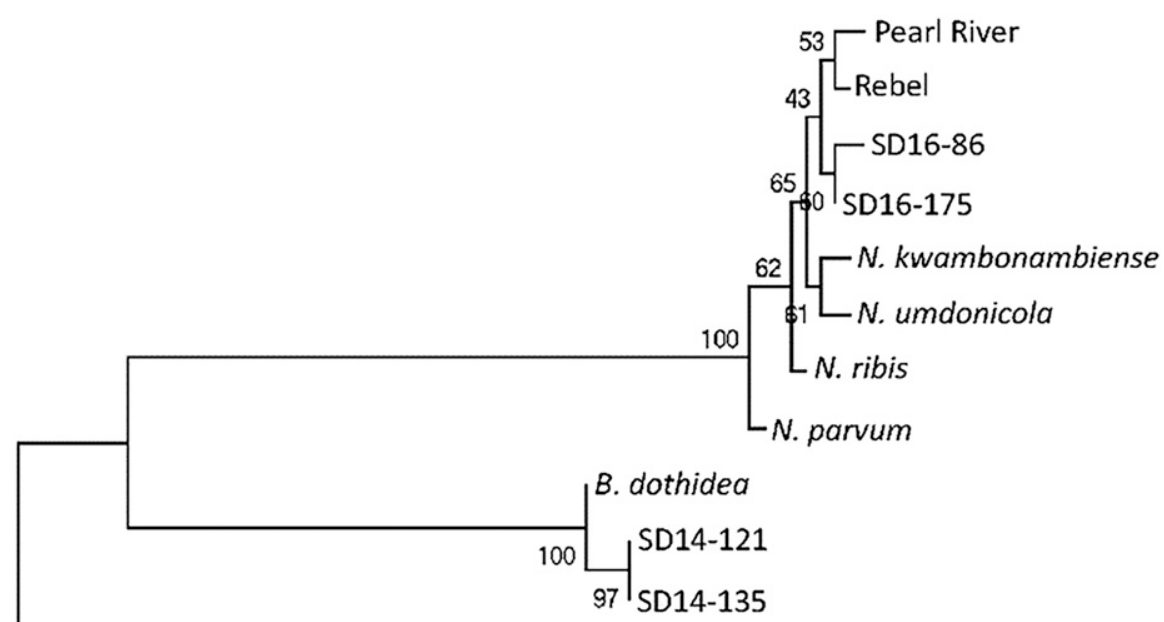

L. theobromae

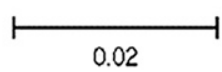

Fig. 1. Neighbor-joining tree based on concatenated ITS and partial EF1- $\alpha$ sequence data. Bootstrap values for 1000 iterations are shown at the branch junctions. Data for vouchered specimens (Neofusicoccum kwambonambiense isolate CBS123639, N. umdonicola isolate CBS123645, N. ribis isolate CBS115475, N. parvum isolate ATCC5891, Botryosphareia dothidea isolate CBS115476, and Lasiodiplodia theobromae isolate CBS16496) were downloaded from GenBank. Bar indicates nucleotide substitutions. 
have used various native Vaccinium species in crosses to incorporate genes for adaptation; however, little is known about Neofusicoccum species identification and the responses of native Vaccinium species to infection. Morphological differentiation between different species of Botryosphaeria and Neofusicoccum may not be accurate because isolate pigmentation varies with temperature (Wright and Harmon, 2010). Differentiation based on multigene sequence analyses has proven to be a more reliable method of differentiation between species (Wright and Harmon, 2010). The objectives of our research were to 1) characterize six isolates of stem blight pathogens based on comparison of the DNA sequences of internal transcribed spacer (ITS) and elongation factor $(E F 1-\alpha), 2)$ determine the optimal temperature for the growth of these isolates, 3) characterize the efficacy of several fungicides in controlling the growth of these isolates, and 4) conduct pathogenicity tests on 39 accessions from different Vaccinium species.

\section{Materials and Methods}

Fungal isolates and molecular characterization. Stems were collected from symptomatic southern highbush blueberry cultivars Rebel and Pearl River and used to obtained isolates labeled as Rebel and Pearl River respectively following a protocol described by Smith (2009). In addition, four isolates, SD14-121, SD14-135, SD16-86, and SD16-175, were obtained from infected blueberry samples collected from the P.E. Marucci Center for Blueberry and Cranberry Research, Chatsworth, NJ, as described by Polashock and Kramer (2006). Genomic DNA was extracted from the mycelium of each isolate following a modified $\mathrm{CTAB}$ method described by Babiker et al. (2012). Two sets of primers were used to amplify the internal transcribed spacer (ITS) of rDNA and a partial sequence of the elongation factor $(E F 1-\alpha)$ from the six isolates following the protocol described by White et al. (1990) and Carbone and Kohn (1999), respectively. Polymerase chain reaction products were analyzed in $1.5 \%$ agarose gel stained with ethidium bromide, and the desired amplification products from the six isolates were purified using Zymoclean gel DNA recovery kit (Zymo Research, Irvine, CA). Purified fragments were cloned into the pGEM-T vector (Promega, Madison, WI) and sequenced using the BigDye-Terminator v3.1 cycle sequencing kit (Applied Biosystems, Foster City, CA) on an ABI3500 Genetic Analyzer (Applied Biosystems). The ITS and EF1- $\alpha$ sequences were concatenated and compared with representative vouchered sequences of Neofusicoccum spp. and Botryosphaeria dothidea downloaded from GenBank. These vouchered data represent sequences from $N$. kwambonambiense isolate CBS123639, $N$. umdonicola isolate CBS123645, N. ribis isolate CBS115475, N. parvum isolate ATCC5891, B. dothidea isolate CBS115476, and the outgroup Lasiodiplodia theobromae isolate CBS16496. Alignment was done using Muscle in Mega6 (Tamura et al., 2013). A bootstrapped neighbor-joining tree was generated using Mega6.

Temperature growth study. To determine the optimal temperature for the growth in culture of five isolates, SD14-121, SD14-135, SD16-86, SD16-175, and Rebel, 5.5-mm plugs from each isolate were placed in the center of $10-\mathrm{cm}$ diameter petri dishes containing potato dextrose agar (PDA). For each isolate, two replicates were incubated in four growth chambers maintained at 20, 25, 30, and $35^{\circ} \mathrm{C}$ in the dark. Colony diameters were measured after 2 and $5 \mathrm{~d}$.

In vitro fungicide sensitivity tests. Isolates SD14-121, SD14-135, SD16-86, SD16-175, and Rebel were tested for their sensitivity to four fungicides registered for blueberry disease management; azoxystrobin (Abound, Syngenta Crop Protection, Greensboro, NC), pyraclostrobin + boscalid (Pristine, BASF Corporation, Research Triangle Park, NC), propiconazole (Orbit, Syngenta Crop Protection, Greensboro, NC), and cyprodinil + fludioxonil (Switch, Syngenta Crop Protection, Greensboro, NC). Stock solutions of propiconazole, pyraclostrobin + boscalid, azoxystrobin, and cyprodinil + fludioxonil at concentration of $41.8 \%, 12.8 \%+25.2 \%$, $22.9 \%$, and $37.5 \%+25 \%$ a.i., respectively, were added into autoclaved and cooled PDA medium. Approximately $25 \mathrm{~mL}$ of the amended PDA were poured into $10-\mathrm{cm}$ diameter petri dishes to obtain $\approx 5$-mm-thick layer of agar. A 5.5-mm plug from each isolate was placed in the center of a petri dish plate containing PDA amended with each fungicide. After $7 \mathrm{~d}$, colony diameter was measured. The percentage of mycelial growth inhibition (MGI) was calculated from the colony diameter in fungicide amended PDA (FA) and nonamended PDA (NA) using the formula

$$
\operatorname{MGI}(\%)=[(\mathrm{NA}-\mathrm{FA}) / \mathrm{NA}] \times 100
$$

Pathogenicity tests. On the basis of results of the temperature growth study, the two fastest growing isolates of the stem blight complex, Rebel and SD16-86, were selected and cultured on PDA. Mycelial plugs from 7-day-old cultures were used to screen 39 accessions representing seven Vaccinium species: V. darrowii Camp $(2 n=2 x=24)$,

Table 1. Analysis of variance probability levels for colony diameter of five stem blight complex isolates at four temperatures after $5 \mathrm{~d}$ growth on potato dextrose agar.

\begin{tabular}{lrrrc}
\hline Source & df & Mean square & $F$ & $\operatorname{Pr}>F$ \\
\hline Isolate & 4 & 291.54 & 61.78 & $<0.0001$ \\
Temperature & 3 & 1562.97 & 331.2 & $<0.0001$ \\
Replicate & 1 & 16.20 & 3.43 & 0.069 \\
Isolate * & 12 & 442.57 & 93.78 & $<0.0001$ \\
\multicolumn{1}{l}{ temperature } & & & & \\
\hline
\end{tabular}

Table 2. Mean colony diameter of five stem blight complex isolates after $5 \mathrm{~d}$ growth on potato dextrose agar across four temperatures $(20,25$, 30 , and $35^{\circ} \mathrm{C}$ ).

\begin{tabular}{lc}
\hline Isolate & Colony diam $(\mathrm{mm})^{2}$ \\
SD16-86 & $85.0 \mathrm{a}$ \\
Rebel & $75.1 \mathrm{~b}$ \\
SD16-175 & $75.4 \mathrm{~b}$ \\
SD14-121 & $76.0 \mathrm{~b}$ \\
SD14-135 & $75.4 \mathrm{~b}$ \\
LSD $(P=0.05)$ & 1.54 \\
\hline
\end{tabular}

${ }^{\mathrm{z}}$ Means followed by different letters are significantly different at $5 \%$ level of probability according to Fisher's protected least significant difference (LSD) test.

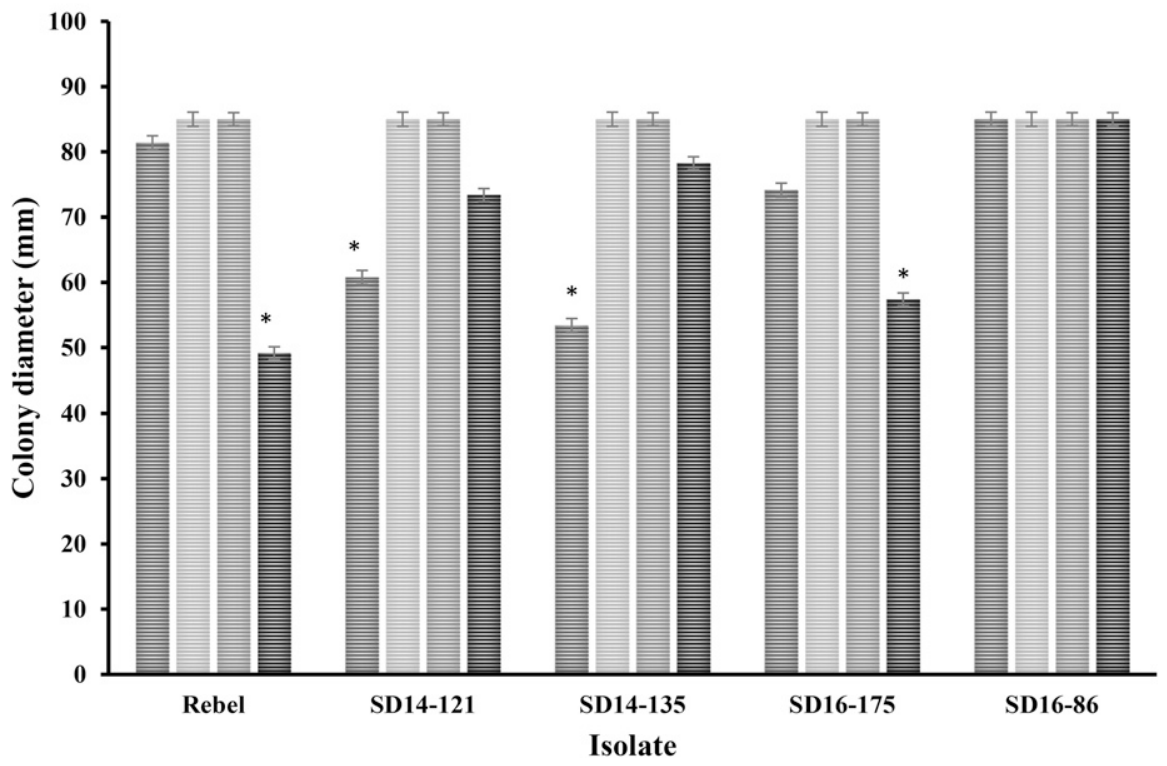

Fig. 2. Colony diameter of five stem blight complex isolates grown on potato dextrose agar incubated at four temperatures after $5 \mathrm{~d}$. Bars indicate $\pm \mathrm{SE}$ of the mean. *Temperature that significantly caused reduction in colony diameter of the tested isolate compared with other temperatures (based on least square mean test at $P=0.05$ ). 
V. elliottii Chapm. $(2 n=2 x=24), V$. stamineum Lam. $(2 n=4 x=48)$, V. arboreum $(2 n=2 x=24), V$. pallidum Ait. $(2 n=2 x=$ 24), $V$. corymbosum $(2 n=4 x=48)$, and $V$. virgatum Aiton. $(2 n=6 x=72)$, using a detached stem assay (Smith, 2009). Briefly, succulent, partially hardened-off stems with similar diameters and 15 to $20 \mathrm{~cm}$ in length were collected from the 39 accessions grown in pots maintained in a greenhouse using pruning shears. All leaves except the terminal three were excised with a razor blade, and the stems were immersed in a beaker with a $10 \%$

Table 3. Analysis of variance probability levels for growth inhibition of five stem blight complex isolates in potato dextrose agar media amended with four fungicides after $7 \mathrm{~d}$.

\begin{tabular}{|c|c|c|c|c|}
\hline Source & $\mathrm{df}$ & Mean square & $F$ & $\operatorname{Pr}>F$ \\
\hline Isolate & 4 & $1,428.17$ & 196.04 & $<0.0001$ \\
\hline Fungicide & 3 & $11,655.83$ & $1,599.92$ & $<0.0001$ \\
\hline Replicate & 2 & 14.16 & 1.94 & 0.1685 \\
\hline $\begin{array}{l}\text { Isolate * } \\
\text { fungicide }\end{array}$ & 12 & 471.89 & 64.77 & $<0.0001$ \\
\hline
\end{tabular}

Means were calculated from three replicates per isolate across two experimental runs.

Table 4. Impact of four fungicides on percentage of growth inhibition of five stem blight complex isolates after $5 \mathrm{~d}$ on fungicide amended agar.

\begin{tabular}{lc}
\hline Fungicide & Percent of inhibition $^{2}$ \\
\hline Azoxystrobin & $35.82 \mathrm{~d}$ \\
Pyraclostrobin + boscalid & $80.39 \mathrm{c}$ \\
Propiconazole & $82.55 \mathrm{~b}$ \\
Cyprodinil + fludioxonil & $88.06 \mathrm{a}$ \\
LSD $(P=0.05)$ & 1.71 \\
\hline
\end{tabular}

${ }^{\mathrm{z}}$ Means followed by different letters are significantly different at $5 \%$ level of probability according to Fisher's protected least significant difference (LSD) test.

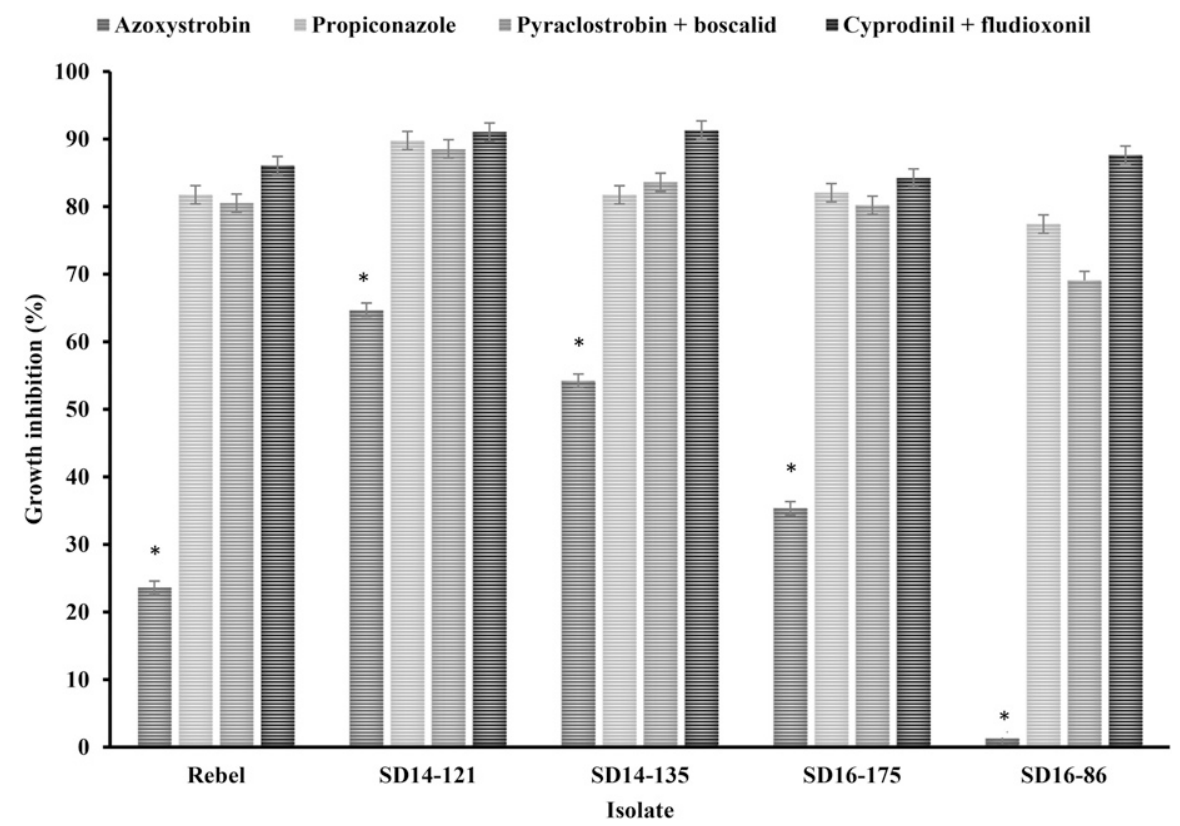

Fig. 3. Percentage of growth inhibition of five stem blight complex isolates grown on potato dextrose agar amended with four fungicides after $7 \mathrm{~d}$. Bars indicate \pm SE of the mean. *Fungicide that significantly caused growth inhibition of the tested isolate compared with other tested fungicides (based on least square mean test at $P=0.05$ ).

solution of sodium hypochlorite for $15 \mathrm{~min}$ followed by dipping in $75 \%$ ethanol for $15 \mathrm{~s}$ and three rinses in sterile deionized water. A small section $(2 \times 10 \mathrm{~mm})$ of the bark from each stem was removed using a sterile scalpel. Mycelial plugs taken from the 7-day-old cultures using a 5.5-mm-diameter sterile cork borer were sealed to the wounded sections using a strip of parafilm. Control stems were treated similarly except that they were mock inoculated with agar plugs from sterile PDA. Stems were inserted into $12-\mathrm{cm}$ test tubes containing $25-\mathrm{mm}$-deep sterile distilled water. Nine stems from each accession were inoculated with each of the two isolates. The experiment was repeated twice. All inoculated and noninoculated stems were incubated in dew chambers maintained at $25^{\circ} \mathrm{C}$ and $\approx 80 \%$ relative humidity with continuous light. After $7 \mathrm{~d}$, the parafilm was removed from each stem and lesion length was measured.

Statistical analysis. Analysis of variance was calculated using proc GLM in SAS (version 9.4; SAS Institute, Cary, NC). All experiments were conducted twice and means of isolates, temperature, and fungicides were compared using Fisher's protected least significant difference at $P=0.05$. Means of temperature $\times$ isolate and accession $\times$ isolate interactions were compared using least square means at $P=0.05$.

\section{Results}

Molecular characterization. The neighbor joining tree generated from the sequence data suggested that the Pearl River, Rebel, SD16-86, and SD16-175 isolates are Neofusicoccum spp., whereas SD14-121 and SD14-135 are B. dothidea (Fig. 1).

Temperature growth study. The temperature and isolate had significant effects on 


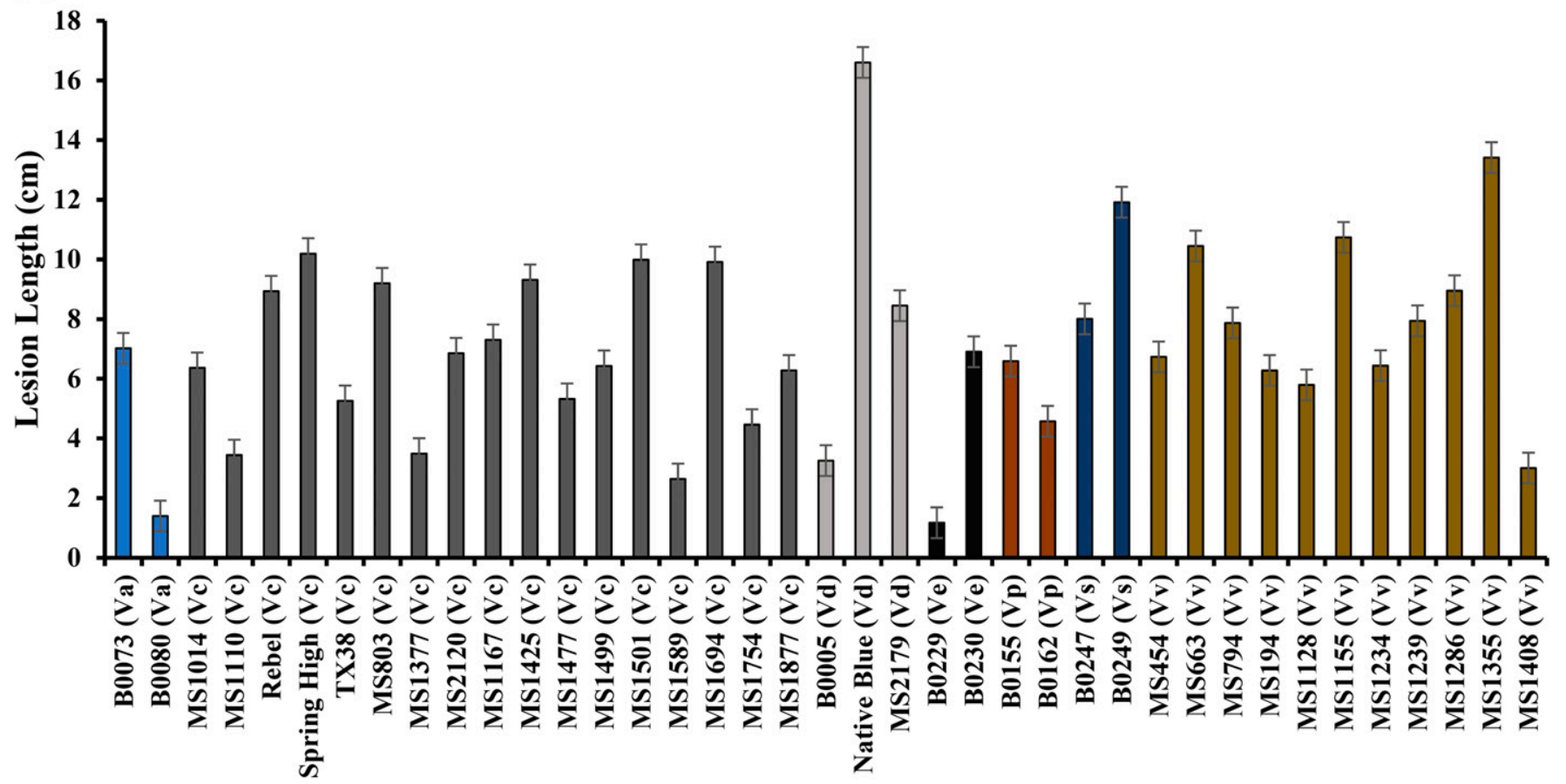

B

Accession

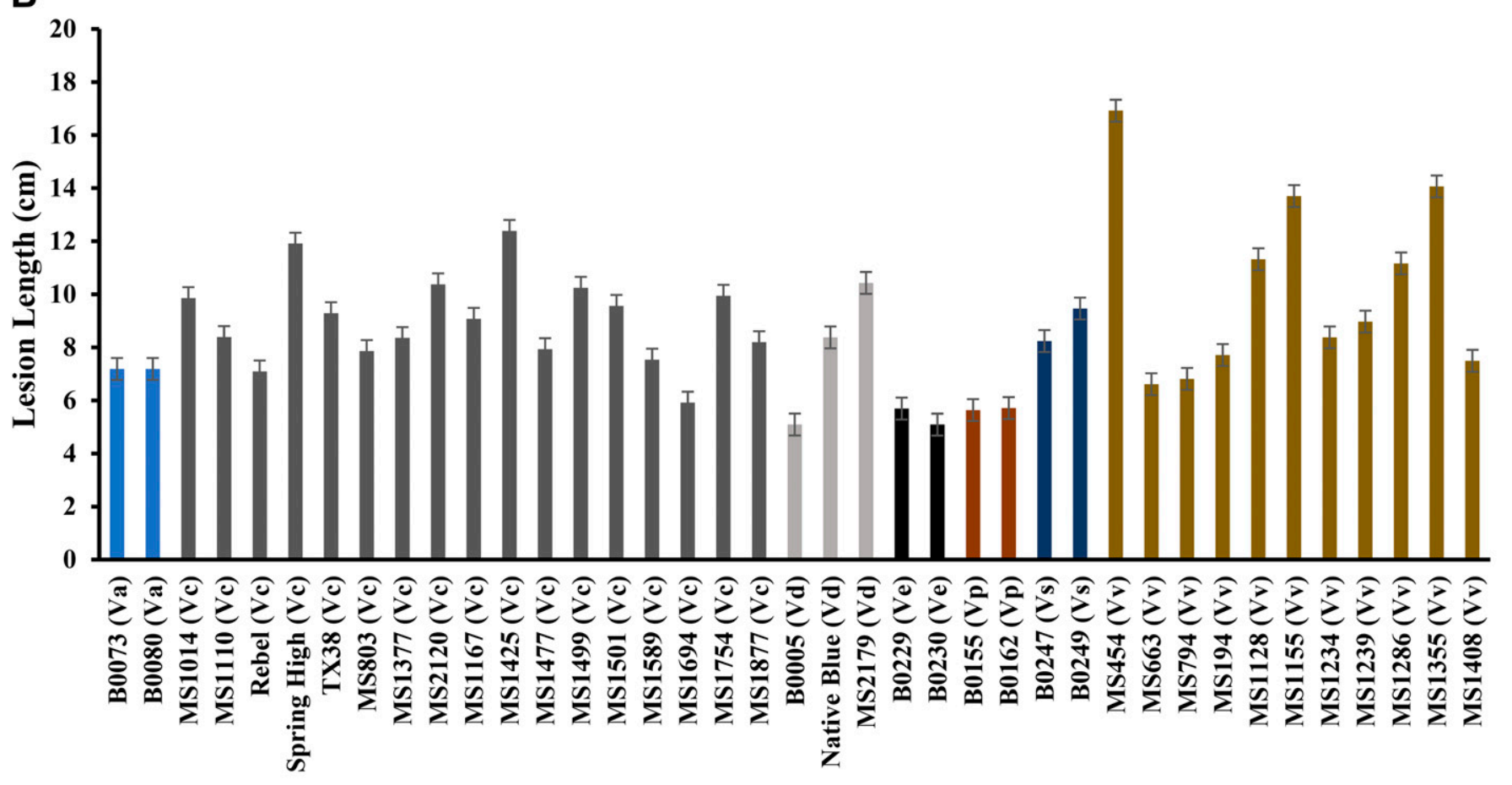

Accession

Fig. 4. Mean lesion length displayed by detached stems of 39 accessions of seven Vaccinium species inoculated with two isolates of stem blight complex in (A) 2017 and $(\mathbf{B})$ 2018. $\mathrm{Vc}=$ Vaccinium corymbosum, $\mathrm{Vv}=$ V. virgatum, $\mathrm{Ve}=$ Vaccinium elliottii, $\mathrm{Vd}=$ V. darrowii, $\mathrm{Va}=$ V. arboreum, $\mathrm{Vs}=$ V. stamineum, and $\mathrm{Vp}=V$. pallidum. Bars indicate $\pm \mathrm{SE}$ of the mean.

genes into widely adapted blueberry cultivars. Breeding for disease resistance relies on finding sources of resistance within cultivated and wild species using the most common and diverse isolates in the region under optimal conditions. Previous studies used in vitro assays to determine the optimal temperature for the growth of stem blight pathogens. Our temperature growth study revealed that the optimal temperature for the growth of isolates Rebel and SD16-175 ranged from 20 to $30{ }^{\circ} \mathrm{C}$, whereas for SD14-121 and SD14-135 ranged from 25 to $30{ }^{\circ} \mathrm{C}$. This variation could be attributed to the fact that isolates SD14-121 and SD14-135 are likely $B$. dothidea, whereas the others are Neofusicoccum spp. This finding is consistent with those of Smith and Miller-Butler (2017a), who reported optimal growth of their $B$. dothidea isolates occurred at 25,30 , and $35{ }^{\circ} \mathrm{C}$, and with Wright and Harmon (2010), who reported that the optimal temperature for the growth of $B$. dothidea, Lasiodiplodia theobromae, N. parvum, and $N$. ribis isolates is $30{ }^{\circ} \mathrm{C}$. In our study, isolate SD16-86, obtained from blueberries in New Jersey, grew over a range of 
Table 5. Analysis of variance of average lesion length $(\mathrm{cm})$ of detached stems of 39 accessions from seven Vaccinium species inoculated with two stem blight complex isolates, SD16-86 and Rebel.

\begin{tabular}{lrrrr}
\hline Source & df & Mean & $F$ & $P r>F$ \\
\hline Year & 1 & 245.87 & 10.12 & 0.0015 \\
Accession & 38 & 106.95 & 4.4 & $<0.0001$ \\
Isolate & 1 & $1,190.38$ & 49.02 & $<0.0001$ \\
Species & 6 & 2.78 & 0.11 & 0.8918 \\
Replicate & 3 & 87.68 & 3.61 & 0.0131 \\
Accession * isolate & 38 & 28.66 & 1.18 & 0.2138 \\
\hline
\end{tabular}

Table 6. Mean lesion length following inoculation of detached stems of 39 accessions from seven Vaccinium species with two stem blight complex isolates in 2017 and 2018 .

\begin{tabular}{lc}
\hline Isolate & Lesion length $(\mathrm{cm})^{z}$ \\
\hline Rebel & $9.81 \mathrm{a}$ \\
SD16-86 & $7.30 \mathrm{~b}$ \\
LSD $(P=0.05)$ & 0.63 \\
\hline
\end{tabular}

${ }^{\mathrm{z}}$ Means followed by different letters are significantly different at 5\% level of probability according to Fisher's protected least significant difference (LSD) test.

temperatures $\left(20\right.$ to $\left.35^{\circ} \mathrm{C}\right)$, whereas colony diameter of cultures of isolate Rebel, obtained from symptomatic stems collected from Mississippi, significantly decreased at $35{ }^{\circ} \mathrm{C}$. Diameter of fungal colonies grown on plates may overestimate the survival potential of isolates; therefore, further field research is needed to confirm this finding.

Results from the fungicide sensitivity tests showed that growing stem blight complex isolates in PDA amended with either of cyprodinil + fludioxonil, propiconazole, pyraclostrobin + boscalid, and azoxystrobin inhibited mycelial growth. Growth inhibition on Switch (cyprodinil + fludioxonil) amended plates was significantly greater than that of plates amended with the other tested fungicides. This finding is consistent with Smith and Miller-Butler (2017b), who reported a significant reduction in stem blight lesion length of detached blueberry stems treated with cyprodinil + fludioxonil. This result could be attributed to the fact that Switch contains two fungicides with different modes of action. Cyprodinil is an anilinopyrimidine that inhibits the methionine biosynthesis pathway, whereas fludioxonil stimulates the synthesis of glycerol, which inhibits fungal mycelial growth (Leroux, 1997). Although Switch (cyprodinil + fludioxonil) is highly effective against tested isolates, the fungicide should be tested according to the fungicide resistance action committee guidelines. Further research is needed to test the efficacy of these fungicides in the field.

Genetic resistance is the most effective means of disease control. Although there are commercial southern highbush blueberry cultivars with moderate levels of resistance to $B$. dothidea (Smith, 2009), responses of southern highbush blueberry cultivars and native Vaccinium species to isolates of the stem blight complex have not been investigated. In this study, the detached stem assay showed the reaction of different accessions from seven Vaccinium species varied across isolates, and none of the tested accessions displayed immunity to either of the two tested isolates. This finding is consistent with Tennakoon et al. (2018), who found pathogenicity of Neofusicoccum differed significantly between species and isolates within a species. Further, no significant difference in lesion length was detected between the different Vaccinium species, suggesting that the host range for stem blight isolates is not limited to cultivated blueberry $(V$. corymbosum and $V$. virgatum). The detached stem assay showed that accessions from the native species, $V$. elliottii and $V$. arboreum, had shorter lesions compared with accessions from $V$. corymbosum and $V$. virgatum. Results from this study are consistent with Ballington et al. (1993), who found $V$. elliottii and $V$. arboreum to be resistant to $B$. dothidea.

The outcome of this study indicates that Neofusicoccum spp. isolate SD16-86 was well adapted to a range of temperatures extending from 20 to $35{ }^{\circ} \mathrm{C}$ and was less sensitive to fungicides compared with other tested isolates. However, isolate Rebel was significantly more aggressive than isolate SD16-86. Three fungicides, cyprodinil + fludioxonil, propiconazole, and pyraclostrobin + boscalid, were effective in in vitro assays against tested isolates of the stem blight complex. Because an association between in vitro fungicide assays and field application was not evaluated in this study, future field research is needed to confirm the efficacy of these fungicides against stem blight incidence. Furthermore, no significant difference in lesion length was detected between the different Vaccinium species, and none of the tested accessions was immune or highly resistance to the tested isolates.

\section{Literature Cited}

Babiker, E.M., S.H. Hulbert, and T.C. Paulitz. 2012. Hyaloperonospora camelinae on Camelina sativa in Washington state: Detection, seed transmission, and chemical control. Plant Dis. 96:1670-1674.

Ballington, J.R., S.D. Rooks, R.D. Milholland, W.O. Cline, and J.R. Meyers. 1993. Breeding blueberries for pest resistance in North Carolina. Acta Hort. 346:87-94.

Boyzo-Marin, J., A. Rebollar-Alviter, H.V. SilvaRojas, and G. Ramirez-Maldonaldo. 2016. First report of Neofusicoccum parvum causing stem blight and dieback of blueberry in Mexico. Plant Dis. 100:2524.

Carbone, I. and L.M. Kohn. 1999. A Method for designing primer sets for speciation studies in filamentous Ascomycetes. Mycologia 91:553556.

Creswell, T.C. and R.D. Milholland. 1988. Spore release and infection periods of Botryosphaeria dothidea on blueberry in North Carolina. Plant Dis. 72:342-346.

Gallardo, K.R., Q. Zhang, M. Dossett, J.J. Polashock, C. Rodriguez-Saona, N. Vorsa, P.P. Edger, H. Ashrafi, E. Babiker, C.E. Finn, and M. Iorizzo. 2018. Breeding trait priorities of the blueberry industry in the United States and Canada. HortScience 53:1021-1028.

Leroux, P. 1997. Recent developments in the mode of action of fungicides. Pest Mgt. Sci. 47:191197.

Milholland, R.D. 1972. Histopathology and pathogenicity of Botryosphaeria dothidea on blueberry stems. Phytopathology 62:654-660.

Polashock, J.J., F.L. Caruso, A.L. Averill, and A.C. Schilder. 2017. Compendium of blueberry, cranberry, and lingonberry diseases and pests. The American Phytopathological Society, St. Paul, MN

Polashock, J.J. and M. Kramer. 2006. Resistance of blueberry cultivars to Botryosphaeria stem blight and phomopsis twig blight. HortScience 41:1457-1461.

Smith, B.J. 2009. Botryosphaeria stem blight of southern blueberries: Cultivar susceptibility and effect of chemical treatments. Acta Hort. 810:385-394.

Smith, B.J. and M.A. Miller-Butler. 2017a Botryosphaeria stem blight on blueberries: Effect of Vaccinium cultivar, Botryosphaeriaceae species and temperature. Acta Hort. 1180:23-30.

Smith, B.J. and M.A. Miller-Butler. 2017b. Effect of nitrogen fertilization and fungicides on Botryosphaeria stem blight lesion development on detached blueberry stems. Acta Hort. 1180:61-70.

Strik, B.C. 2006. Blueberry production and research trends in North America. Acta Hort. 715:173-183.

Tamura, K., G. Stecher, D. Peterson, A. Filipski, and S. Kumar. 2013. Molecular Evolutionary Genetics Analysis version 6.0. Mol. Biol. Evol. 30:2725-2729.

Tennakoon, K.M.S., H.J. Ridgway, M.V. Jaspers, and E.E. Jones. 2018. Botryosphaeriaceae species associated with blueberry dieback and sources of primary inoculum in propagation nurseries in New Zealand. Eur. J. Plant Pathol. 150:363-374.

Weaver, D.J. 1978. Role of conidia of Botryosphaeria dothidea in the natural spread of peach tree gummosis. Phytopathology 69:330-334.

White, T.J., T. Bruns, S. Lee, and J. Taylor. 1990 Amplification and direct sequencing of fungal ribosomal RNA genes for phylogenetics, $\mathrm{p}$. 315-322. In: PCR Protocols: A guide to methods and applications. Academic Press, Cambridge, MA.

Wright, A.F. and P.F. Harmon. 2010. Identification of species in the Botryosphaeriaceae family causing stem blight on southern highbush blueberry in Florida. Plant Dis. 94:966-971.

Yu, L., I. Rarisara, S.G. Xu, X. Wu, and J.R. Zhao. 2012. First report of stem blight of blueberry caused by Botryosphaeria dothidea in China. Plant Dis. 96:1697. 